\title{
Challenges in the Management of a Case of Secondary Abdominal Pregnancy
}

\author{
Alpana Singh, Vandana Mishra*, Yashika Motwani, Pragati Meena \\ UCMS \& GTB Hospital, New Delhi, India \\ Email: drvanu123@gmail.com \\ Received 3 February 2015; accepted 25 September 2015; published 28 September 2015 \\ Copyright (C) 2015 by authors and Scientific Research Publishing Inc. \\ This work is licensed under the Creative Commons Attribution International License (CC BY). \\ http://creativecommons.org/licenses/by/4.0/ \\ (c) (i) Open Access
}

\begin{abstract}
Introduction: Abdominal pregnancy, one of the rare forms of ectopic pregnancy demands a high index of suspicion for its timely diagnosis and intervention so as to prevent both maternal and neonatal complications. We presented a case of secondary abdominal pregnancy which was missed at the first instance at a private centre and came to us with nonspecific abdominal symptoms after an attempted termination of pregnancy by surgical means (dilation and curettage). Case presentation: A 24-year-old third gravida with two live issues at $\mathbf{1 0}$-week gestation came to us with complaints of pain lower abdomen, vomiting and inability to pass stool. She gave history of undergoing dilation and curettage $(D \& C)$ at a private hospital for termination of pregnancy about 20 days back. After thorough work-up and investigations, the diagnosis of secondary abdominal pregnancy was established and she was taken up for exploratory laparotomy with the removal of fetus with placenta. The patient progressed well with the postoperative period remaining uneventful. Conclusion: Secondary abdominal pregnancy poses as a challenge to clinicians working with limited diagnostic facilities. The condition may be life threatening if not handled meticulously.
\end{abstract}

\section{Keywords}

Secondary Abdominal Pregnancy, Uterus

\section{Introduction}

Abdominal pregnancy is the implantation in peritoneal cavity exclusive of tubal, ovarian or intra-ligamentary pregnancy [1]. It may be primary or secondary, reported incidence being 1 in 10,000 deliveries [2]. Risk of maternal mortality is around $4 \%-29 \%$ and fetal mortality is to the tune of $75 \%-95 \%$ [3].

"Corresponding author.

How to cite this paper: Singh, A., Mishra, V., Motwani, Y. and Meena, P. (2015) Challenges in the Management of a Case of Secondary Abdominal Pregnancy. Open Journal of Obstetrics and Gynecology, 5, 669-671. 
Secondary abdominal pregnancy results from early tubal abortion or rupture or uterine scar dehiscence with secondary implantation of pregnancy in the abdominal cavity. The placenta spreads through the wall of tube or is aborted through the fimbrial end and retains some attachment with tube which supplies blood to continue development in the new peritoneal site.

\section{Case Summary}

We present the case of a 24-year-old third gravida, para 2 with two live issues at 10 -week gestation who came with history of undergoing dilation and curettage (D\&C) for the termination of her pregnancy 20 days back, with the complaints of pain lower abdomen and dizziness since 1 week and vomiting and inability to pass stool since 3 days.

On general physical examination she was found to be clinically severely pale, pulse rate was 110/min and BP was 120/70 mmHg. Per abdominal examination showed distension, guarding and rigidity with presence of diffuse tenderness. On per vaginal examination uterus was found to be corresponding to 10 week gestation and deviated to right. Left fornix was free. A provisional diagnosis based on clinical examination was made of G3P2L2 with single live intrauterine fetus of 10-week gestation with intestinal perforation/intestinal obstruction/uterine perforation/abdominal Koch’s.

Initial investigations revealed hemoglobin-8 g\%, TLC $-15.200 / \mathrm{cu} \mathrm{mm}$, Platelet count $-1,10,000 / \mathrm{cu} \mathrm{mm}$, PT/PTTK-13/32 sec, trans-vaginal scan-single live intra-uterine fetus corresponding to 12-week gestation with no adnexal mass. Montoux test was negative. Abdominal X-ray showed distended bowel loops with no gas under diaphragm. USG whole abdomen showed moderate ascites. Patient was put on conservative management for 2 weeks.

Patient was reevaluated after 2 weeks when abdominal distension and guarding had decreased. Abdominal examination showed fundal height more than gestational age. A repeat vaginal examination was done which showed a mass 16 week gestation in right adnexa separate from uterus. Abdominal scan showed single live intra uterine fetus with right ovarian cyst with internal septations hemorrhagic cyst. TVS was done for evaluation of ovarian cyst by a senior consultant who revealed extra uterine SLF 12-week gestation, uterus was normal in size with mild free fluid in peritoneal cavity. Her b-hcg was 10,000. Diagnosis of right ovarian ectopic/abdominal pregnancy was made.

Exploratory laparotomy was conducted. Intraoperatively, definite diagnosis of secondary abdominal pregnancy was made. Omentum was adherent to lower abdominal wall. Gestational sac with placenta was adherent to posterior surface of broad ligament near right cornua. Uterus, bilateral tubes and ovaries were normal. Removal of gestational sac was attempted which lead to sudden profuse bleeding. 2-unit whole blood was transfused. Placenta and fetus were extracted. The patient remained uneventful in post-operative period and was discharged after 10 days.

\section{Discussion}

Abdominal pregnancy is a rare obstetrical complication with high maternal and fetal mortality. This is most likely a case of uteroabdominal pregnancy following uterine rupture at time of termination of pregnancy. The embryo might have migrated through the rent in uterus to establish in the peritoneal cavity. It is most likely a case of attempted termination of pregnancy by untrained personnel.

About 50\% cases are missed on USG [4]. CT and MRI are excellent tools to diagnose secondary abdominal pregnancy [5]. In our case, clinical diagnosis was delayed. Diagnosis was also initially missed on USG. Later, clinical and radiologic correlation helped to overcome the diagnostic dilemma.

During surgery, thick adhesions commonly found in abdominal pregnancy pose major surgical challenge as seen in the above case. The decision regarding fate of placenta is a common operative dilemma. Decision rests on intra-operative findings. If placenta is easily accessible and its removal can be accomplished without excessive blood loss, it should be removed completely. If vascular attachments involve major blood vessels or vital structures, it should be left undisturbed [6]. Retention of placenta is associated with risks of secondary hemorrhage, abscess, paralytic ileus and bowel obstruction.

Modalities which reduce intra-operative vascularity would be a boon to these patients. Pre-operative arterial embolisation and methotrexate therapy have been advocated [7]. Post-operative methotrexate has been recommended by some but rapid placental destruction may lead to accumulation of necrotic debris inviting bacterial 
growth [8].

\section{Conclusion}

Early proper preoperative evaluation, availability of sufficient blood products, multidisciplinary team and proper operative techniques in managing abdominal pregnancy can reduce maternal morbidity and mortality.

\section{References}

[1] Worley, K.C., Hnat, M.D. and Cunningham, F.G. (2008) Advanced Extra Uterine Pregnancy: Diagnostic and Therapeutic Challenges. American Journal of Obstetrics \& Gynecology, 198, 297. http://dx.doi.org/10.1016/j.ajog.2007.09.044

[2] Atrash, H.K., Friede, A. and Hogue, C.J. (1987) Abdominal Pregnancy in the United States. Frequency and Maternal Mortality. Obstetrics \& Gynecology, 69, 333.

[3] Mark, A. and John, A. (2009) Ectopic Pregnancy. In: Jones, H.W., Ed., Te Linde’s Operative Gynecology, 10th Edition, Wolters Kluwer Health/Lippincott Williams \& Wilkins, Philadelphia.

[4] Costa, S.D., Presley, J. and Bastert, G. (1991) Advanced Abdominal Pregnancy. Obstetrical \& Gynecological Survey, 46, 515-525. http://dx.doi.org/10.1097/00006254-199108000-00003

[5] Cunningham, G.F., Levine, K.J. and Bloom, S.I. (2005) Williams Obstetrics. 22nd Edition, Prentice Hall International, UK, 265-266.

[6] Hallatt, J.G. and Grove, J.A. (1985) Abdominal Pregnancy: A Study of 21 Consecutive Cases. American Journal of Obstetrics \& Gynecology, 152, 444-448. http://dx.doi.org/10.1016/S0002-9378(85)80155-1

[7] Rahaman, J., Berkowitz, R. and Mitty, H. (2004) Minimally Invasive Management of an Advanced Abdominal Pregnancy. Obstetrics \& Gynecology, 103, 1064-1068. http://dx.doi.org/10.1097/01.AOG.0000127946.14387.48

[8] Robert, R.V., Dickinson, J.E., Leung, Y. and Charles, A.K. (2005) Advanced Abdominal Pregnancy: Still an Occurence in Modern Medicine. Australian and New Zealand Journal of Obstetrics, 45, 518-521.

http://dx.doi.org/10.1111/j.1479-828X.2005.00489.x 